Tohoku J. Exp. Med., 2012, 226, 171-175

Invited Review

\title{
The Current Endeavors to Understand the Pathogenesis of Intractable Liver Diseases
}

\author{
Yoshiyuki Ueno ${ }^{1}$ \\ ${ }^{1}$ Department of Gastroenterology, Yamagata University Faculty of Medicine, Yamagata, Japan
}

\begin{abstract}
The death due to liver diseases accounts for more the 35,000 cases every year in Japan for decades. Among these liver diseases, the Ministry of Health, Labor, and Welfare of Japan has named both fulminant hepatitis and primary biliary cirrhosis (PBC) as intractable liver diseases, since the precise mechanism of these diseases are unclear. Accordingly, there are no effective medical treatments other than liver transplantation toward these diseases. However, still the number of the liver transplantation performed in Japan is small. Thus, we have focused on the pathogenesis of these two intractable conditions. The fulminant hepatitis is a distinct form of acute hepatitis, and hepatitis B virus infection accounts for 20 30\% of this lethal condition. Only tiny proportions of patients with acute HBV infection develop fulminant hepatitis (less than 10\%). It has been widely believed both viral and host factors contribute for fulminant hepatitis, although still unknown factors are expected to be involved. On the other hand, PBC is a chronic progressive cholestatic liver disease. Clinical features of PBC include female predominance (80 to $90 \%$ ), the presence of antimitochondrial antibody (up to 95\%), and elevated serum levels of immunoglobulin $\mathrm{M}$. Eventually, patients with PBC will develop liver failure due to biliary cirrhosis in spite of medical interventions. Immune-mediated processes are believed to be responsible for the pathogenesis, although the precise mechanism is yet to be determined. In this review article, our endeavors to understand the mechanism of these intractable liver diseases are discussed.
\end{abstract}

Key words: fulminant hepatitis; hepatitis B virus; intractable liver diseases; liver failure; primary biliary cirrhosis Tohoku J. Exp. Med., 2012, 226 (3), 171-175. C 2012 Tohoku University Medical Press

For past 30 years, the death due to liver diseases accounts for more than 30,000 Japanese every year. Among these deaths, the hepatocellular carcinoma (HCC) has been major cause of liver related death in Japan (Ueno et al. 2009) In the early time of this period, the Hepatitis $C$ virus (HCV) was not discovered, and thus so-called non-A non-B hepatitis was the most possible cause of HCC in Japan. Soon after the discovery of HCV in the end of 1980s, the majorities of non-A non-B hepatitis were proven to be actually HCV-related liver diseases. Moreover, the introduction of preventive measures to avoid iatrogenic $\mathrm{HCV}$ transmission, namely transfusion related infections, dramatically decreased newly infection in early 1990s (Amarapurkar et al. 2009). Thus, the most important clinical issues were focused on how to manage and treat the people with established HCV infections. Fortunately, the recent progress of treatment of $\mathrm{HCV}$ made possible for eradication of virus from human body in nearly half of the genotype $1 \mathrm{~b}$ type (difficult to treat genotype) and more than $80 \%$ of other genotypes (Kogure et al. 2008; Kumada et al. 2010a). Also, chronic hepatitis B virus (HBV) infection is responsible for approximately $10 \%$ of HCC in Japan (Mikami et al. 2007). Before the year of 2000, there are number of the cases with liver failure due to chronic HBV infection. However, after the introduction of nuleot(s)ide analogues, the amount of HBV levels were controllable in the majority of the cases, which has been demonstrated as the decreased number of liver failure derived from chronic HBV infection (Kumada et al. 2010b; Inoue et al. 2011a, 2011c) (Fig. 1). Given these observations, the challenge for researchers studying liver diseases has been shifted to intractable liver diseases, rather than controllable common diseases. Currently, the Japanese Ministry of Health, Labor, and Welfare has named both fulminant hepatitis and primary biliary cirrhosis (PBC) as intractable liver diseases, and give financial supports as the grant in aid for intractable liver diseases. In this review article, the current trends and efforts to understand the pathogenesis of these two diseases are provided.

Received January 11, 2012; revision accepted for publication February 1, 2012. doi: 10.1620/tjem.226.171

Correspondence: Yoshiyuki Ueno, M.D., Ph.D., Department of Gastroenterology, Yamagata University Faculty of Medicine, 2-2-2

Iidanishi, Yamagata 9909585, Japan.

e-mail: y-ueno@med.id.yamagata-u.ac.jp

Dr. Yoshiyuki Ueno is a recipient of the 2010 Gold Prize, Tohoku University School of Medicine. 


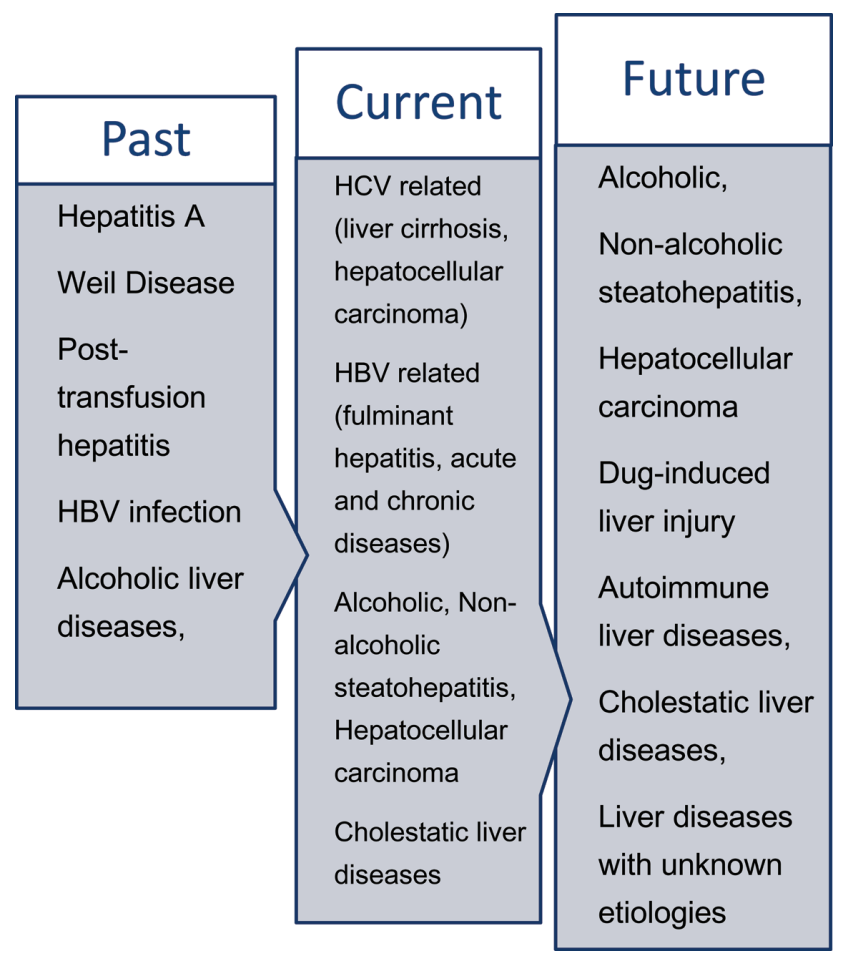

Fig. 1. Trends in the morbidity of liver diseases in Japan. HAV: hepatitis A virus, HBV: hepatitis B virus

\section{Fulminant Hepatitis}

Fulminant hepatitis (FH) is a strange form of acute hepatitis. In Japan, the term 'fulminant hepatitis' is used for fatal form of acute viral hepatitis. This is very characteristic, since most of Western country uses the term 'fulminant hepatic failure', including drug-induced acute liver toxicities such as acetaminophen overdoses. Although the term has not been uniformed globally, this acute condition often demonstrates serious clinical courses, leading to more than $30-40 \%$ of mortality in acute form. In Japan, thus acute viral infection, especially acute hepatitis B virus (HBV) infection is a major cause of this fatal disease. HBV infection is one of the most common viral diseases affecting humans. HBV causes a diverse group of liver diseases such as acute hepatitis, chronic hepatitis, liver cirrhosis, and hepatocellular carcinoma. Acute infection of HBV sometimes leads to fulminant hepatitis B (FHB), which is lethal during a short period in many cases. Indeed, we have experienced this emergent condition several times, which has been successfully treated with liver transplantation (Inoue et al. 2005). In fact, only a tiny proportion of patients with acute hepatitis B will develop FHB, in which the precise mechanism of pathogenesis has not been clarified (Fig. 2). Both viral factors and human (host) factors are believed to be important for the pathogenesis of FHB. Several mutations in the Core promoter and Precore region of HBV, especially a mutation at 1896 in Core region, were reported to be associated with the development of FHB. However, some conflicting results have been described about specific

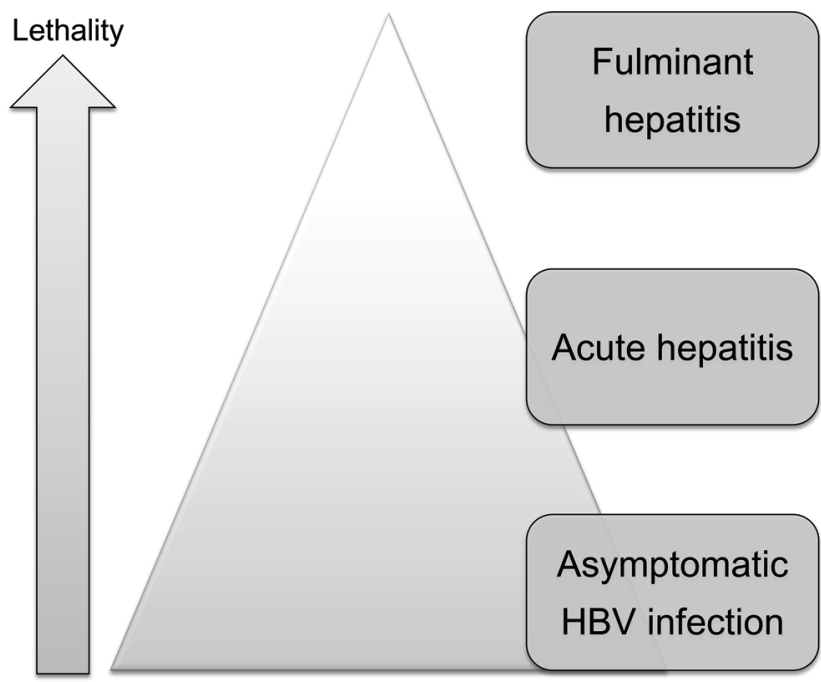

Fig. 2. Scheme of acute HBV infection.

Only tiny portions of patients with acute HBV infection develop fulminant hepatitis.

viral factors for the pathogenesis of FHB. Accordingly, there are still unknown mechanisms in regard to the pathogenesis of FHB.

In the year of 2000 , seven patients with FHB were referred to Tohoku University Hospital, Sendai. More importantly, these cases were supposed to be derived from a single person who had been persistently infected with a specific HBV strain. Thus, in these specific cases of FHB, viral factors rather than host factors seemed to be more important for developing $\mathrm{FH}$, since six of seven proven infected person with this HBV strain developed fulminant hepatitis. Unfortunately, five of six patients with this FHB deceased with acute liver failure. Thus, we have tried to clarify the viral factors to cause FHB from this series of FHB (Nagasaki et al. 2008).

First, we have performed the full-genome sequencing with this HBV strain to find out specific mutations. We have found that this viral strain belongs to HBV genotype $\mathrm{Ba}$, which is reported to be typical in Asian region, and different from genotype $\mathrm{Bj}$, which is dominant genotype of acute HBV infection in Japan. Next, we have done in vitro experiments to further investigate the mechanism of pathogenesis of FHB induced by this specific HBV strain (Inoue et al. 2009). To do this, we constructed vectors consisting of x1.3 length full-genome cDNA insert of HBV strain, as well as mutated inserts at various positions. Using this in vitro experimental system, we have found that i) the mutation found in this HBV strain caused dramatic increase of viral replication, ii) replicated virion accumulated in cytoplasm of hepatocytes, implicating potential cytotoxicity due to these accumulations, and iii) the mutation in pre-Core region and Core region of HBV caused enhanced transcriptional activities (Inoue et al. 2011b). Taken together, we have shown that specific HBV stain that caused series of FHB in the year of 2000 in Sendai area showed 1) potent 


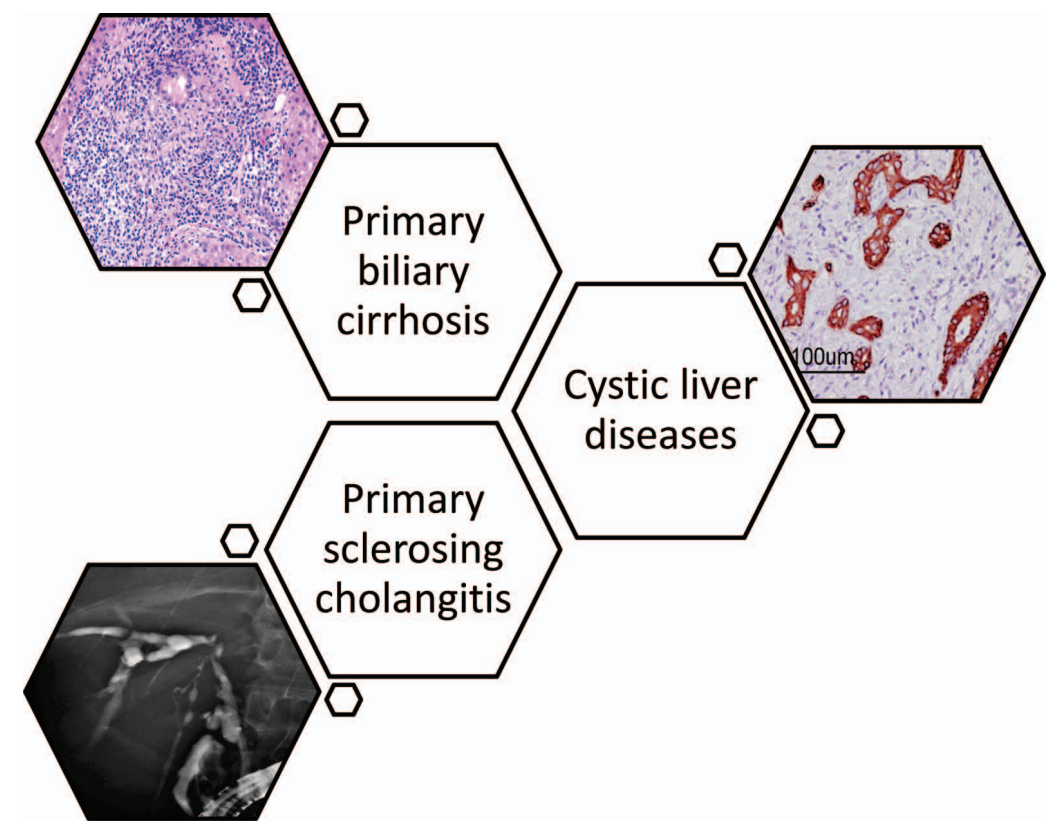

Fig. 3. Diverse groups of cholestatic liver diseases.

The representative human cholestatic liver diseases are listed. The pathogenesis of most of these diseases remains to be unclear.

replicative activity which is advantage for increased number of infected hepatocytes and 2) increased accumulation of virion in host's hepatocytes, leading to increased cytotoxicity. Thus, viral factors seemed to be more important and influential in FHB caused by this specific viral strain. Of course, more factors other than viral factors could be involved in the pathogenesis of FHB, although our experienced viral strain is the first case of reproducible fatale viral strain. Thus, future studies should include more sensitive methods to detect dangerous these viral factors in practice.

\section{Primary Biliary Cirrhosis (PBC)}

$\mathrm{PBC}$ is also named as intractable liver disease by Japanese Ministry of Health, Labor, and Welfare. This rare disease could be summarized as chronic chloestatic liver disease, resulting in biliary cirrhosis and finally in liver failure (Ueno et al. 2007) as like other liver diseases such as primary sclerosing cholangitis (Fig. 3). In its early stage, ursodeoxycholic acid (UDCA) was reported to be effective in stand of the prolonged time needed for liver transplantation (Poupon et al. 1997). However, in the advanced stage, only liver transplantation is an effective option for improving the survival. Although the bile duct injury is executed by infiltrating lymphocytes, the application of corticosteroids, usually effective in other immune-mediated collagen diseases, is generally ineffective. Pathologically, this bile duct destruction is observed mainly in interlobular bile ducts, whereas larger (septal) or smaller (ductile) ducts are essentially preserved from injury. Thus, the size of the bile duct is characteristic and important in the pathogenesis of PBC. We have paid most of our attention on this selectivity of the bile duct to understand the pathogenesis of PBC.
First of all, the bile duct epithelial cells or cholangiocytes represent less than $3 \%$ of liver parenchymal cells. Until late 1980s, when the isolation and culture of cholangiocytes became possible, their physiological and cellular functions were poorly understood. Subsequently, along with the advancement of molecular techniques, the studies of cholangiocytes have been progressed rapidly. For example, we have demonstrated the expression of aquaporin 1 by cholangiocytes, which are influenced by hepatic inflammation (Roberts et al. 1994; Tamai et al. 2006). We have also proposed the idea of heterogeneity of cholangiocytes, and this idea has been proved physiologically and molecularly (Alpini et al. 1996, 1997). The heterogeneity includes the differences in the mechanism of cell death and intracellular pathway toward choleresis via PKC or cAMP (Alpini et al. 2001). Moreover, like the heterogeneity of renal tubules, large cholangiocytes have the different phenotype regarding molecular or physiological aspects (Lesage et al. 2001; Ueno et al. 2003). These studies about the understanding of the heterogeneity of cholangiocytes will contribute to answering the key question regarding the selective destruction of bile ducts seen in PBC. Recently, we have applied 2-dimension gel electrophoresis to perform proteomics study (Kido et al. 2009). With this sophisticated technique, we found that the expression of annexin A2 was increased in cholangiocytes when exposed to inflammatory cytokines. In addition, the artificial regulation of this molecule could affect choleresis, and thus the modification of the expression of annexin A2 could be a possible therapeutic application for the management of clinical cholestasis.

Apart from these cellular studies, several efforts have been done to establish animal models of PBC (Ueno et al. 
1996, 2010; Moritoki et al. 2007, 2009a, 2009b: Chuang et al. 2008). Among them, we have found that CD95, a key antigen to execute apoptosis, plays central role in the pathogenesis of the cholangiocyte injury in both mouse graft versus host disease and NODc3c4 cholangiopathies (Ueno et al. 2000; Nakagome et al. 2007). The inhibition of CD95 also suppressed cytotoxicity in the graft versus host disease model.

More recently, the retrovirus infection was reported as a possible pathogen for pathogenesis of $\mathrm{PBC}$ (Xu et al. 2003). However, we could not find these viral derived endogenous genes specifically from serum samples obtained from patients with PBC. Moreover, therapeutic effects of administration of reverse transcriptase inhibitor, lamivudine, were not apparent in UDCA-refractory patients in randomized controlled trial (Fukushima et al. 2010). However, since a part of retroviral gene was found in liver sample from female NODc3c4 mice (Ninomiya et al. 2012), still the involvement of retorovirus in the pathogenesis of $\mathrm{PBC}$ remains to be unclear.

\section{Closing remarks}

In this review article, the current endeavors to understand the pathogenesis of intractable liver diseases were introduced using FH and PBC. However, other than these two diseases, there are numbers of other liver diseases, such as liver cirrhosis, non-alcoholic fatty liver diseases, which are expected to increase in next decades (Kakazu et al. 2009; Obara et al. 2010; Kakazu et al. 2011). Obviously, still more efforts to understand these liver diseases are important to improve global healthcare.

\section{Acknowledgments}

The receipt of the 2010 Gold Prize from Tohoku University School of Medicine was possible only with the outstanding mentorship from Professor Tooru Shimosewaga, and outstanding colleagues in hepatologists group at Tohoku University Graduate School of Medicine. Also, we are grateful for numbers of paramedics and technicians for supporting our experiments, especially staffs in experimental animal facility and cell culture laboratory.

\section{Conflict of Interest}

The author does not have potential conflict of interest regarding this review article.

\section{References}

Alpini, G., Roberts, S., Kuntz, S.M., Ueno, Y., Gubba, S., Podila, P.V., LeSage, G. \& LaRusso, N.F. (1996) Morphological, molecular, and functional heterogeneity of cholangiocytes from normal rat liver. Gastroenterology, 110, 1636-1643.

Alpini, G., Ueno, Y., Glaser, S.S., Marzioni, M., Phinizy, J.L., Francis, H. \& Lesage, G. (2001) Bile acid feeding increased proliferative activity and apical bile acid transporter expression in both small and large rat cholangiocytes. Hepatology, 34, 868-876.

Alpini, G., Ulrich, C., Roberts, S., Phillips, J.O., Ueno, Y., Podila, P.V., Colegio, O., LeSage, G.D., Miller, L.J. \& LaRusso, N.F. (1997) Molecular and functional heterogeneity of cholangio- cytes from rat liver after bile duct ligation. Am. J. Physiol., 272, G289-297.

Amarapurkar, D., Han, K.H., Chan, H.L. \& Ueno, Y. (2009) Application of surveillance programs for hepatocellular carcinoma in the Asia-Pacific Region. J. Gastroenterol. Hepatol., 24, 955-961.

Chuang, Y.H., Ridgway, W.M., Ueno, Y. \& Gershwin, M.E. (2008) Animal models of primary biliary cirrhosis. Clin. Liver Dis., 12, 333-347.

Fukushima, K., Ueno, Y. \& Shimosegawa, T. (2010) Treatment of Primary Biliary Cirrhosis: A new challenge? Hepatol. Res., 40, 61-68.

Inoue, J., Ueno, Y., Kanno, N., Anzai, H., Kondo, Y., Moritoki, Y., Mikami, E., Chiba, M., Kogure, T., Nagasaki, F., Fukushima, K., Iwasaki, T., Satomi, S. \& Shimosegawa, T. (2005) Living related liver transplantation for acute fulminant hepatitis B: experience from two possible hyper-acute cases. Tohoku J. Exp. Med., 205, 197-204.

Inoue, J., Ueno, Y., Nagasaki, F., Wakui, Y., Kondo, Y., Fukushima, K., Niitsuma, H. \& Shimosegawa, T. (2009) Enhanced intracellular retention of a hepatitis B virus strain associated with fulminant hepatitis. Virology, 395, 202-209.

Inoue, J., Ueno, Y. \& Shimosegawa, T. (2011a) Management of chronic hepatitis B patients: Efficacy \& limitation of nucleos(t)ide analogues. Indian. J. Med. Res., 133, 11-14.

Inoue, J., Ueno, Y., Wakui, Y., Fukushima, K., Kondo, Y., Kakazu, E., Ninomiya, M., Niitsuma, H. \& Shimosegawa, T. (2011b) Enhanced replication of hepatitis B virus with frameshift in the precore region found in fulminant hepatitis patients. $J$. Infect. Dis., 204, 1017-1025.

Inoue, J., Ueno, Y., Wakui, Y., Niitsuma, H., Fukushima, K., Yamagiwa, Y., Shiina, M., Kondo, Y., Kakazu, E., Tamai, K., Obara, N., Iwasaki, T. \& Shimosegawa, T. (2011c) Four-year study of lamivudine and adefovir combination therapy in lamivudine-resistant hepatitis B patients: influence of hepatitis B virus genotype and resistance mutation pattern. J. Viral. Hepat., 18, 206-215.

Kakazu, E., Ueno, Y., Kondo, Y., Fukushima, K., Shiina, M., Inoue, J., Tamai, K., Ninomiya, M. \& Shimosegawa, T. (2009) Branched chain amino acids enhance the maturation and function of myeloid dendritic cells ex vivo in patients with advanced cirrhosis. Hepatology, 50, 1936-1945.

Kakazu, E., Ueno, Y., Kondo, Y., Inoue, J., Ninomiya, M., Kimura, O., Wakui, Y., Fukushima, K., Tamai, K. \& Shimosegawa, T. (2011) Plasma L-Cystine/L-Glutamate Imbalance Increases Tumor Necrosis Factor-Alpha from CD14+ Circulating Monocytes in Patients with Advanced Cirrhosis. PLoS One, 6, e23402.

Kido, O., Fukushima, K., Ueno, Y., Inoue, J., Jefferson, D.M. \& Shimosegawa, T. (2009) Compensatory role of inducible annexin A2 for impaired biliary epithelial anion-exchange activity of inflammatory cholangiopathy. Lab. Invest., 89, 1374-1386.

Kogure, T., Ueno, Y., Fukushima, K., Nagasaki, F., Kondo, Y., Inoue, J., Matsuda, Y., Kakazu, E., Yamamoto, T., Onodera, H., Miyazaki, Y., Okamoto, H., Akahane, T., Kobayashi, T., Mano, Y., Iwasaki, T., Ishii, M. \& Shimosegawa, T. (2008) Pegylated interferon plus ribavirin for genotype $\mathrm{Ib}$ chronic hepatitis $\mathrm{C}$ in Japan. World J. Gastroenterol., 14, 7225-4230.

Kumada, H., Okanoue, T., Onji, M., Moriwaki, H., Izumi, N., Tanaka, E., Chayama, K., Sakisaka, S., Takehara, T., Oketani, M., Suzuki, F., Toyota, J., Nomura, H., Yoshioka, K., Seike, M., Yotsuyanagi, H. \& Ueno, Y. (2010a) Guidelines for the treatment of chronic hepatitis and cirrhosis due to hepatitis B virus infection for the fiscal year 2008 in Japan. Hepatol. Res., 40, 1-7.

Kumada, H., Okanoue, T., Onji, M., Moriwaki, H., Izumi, N., Tanaka, E., Chayama, K., Sakisaka, S., Takehara, T., Oketani, M., Suzuki, F., Toyota, J., Nomura, H., Yoshioka, K., Seike, 
M., Yotsuyanagi, H. \& Ueno, Y. (2010b) Guidelines for the treatment of chronic hepatitis and cirrhosis due to hepatitis $\mathrm{C}$ virus infection for the fiscal year 2008 in Japan. Hepatol. Res., 40, 8-13.

Lesage, G., Glaser, S., Ueno, Y., Alvaro, D., Baiocchi, L., Kanno, N., Phinizy, J.L., Francis, H. \& Alpini, G. (2001) Regression of cholangiocyte proliferation after cessation of ANIT feeding is coupled with increased apoptosis. Am. J. Physiol. Gastrointest. Liver Physiol., 281, G182-190.

Mikami, E., Kanno, N., Ueno, Y. \& Shimosegawa, T. (2007) Retrospective evaluation of tumor-mass-reduction therapy for the prognosis of recurrent hepatocellular carcinoma. Hepatol. Int., 1, 460-469.

Moritoki, Y., Lian, Z.X., Lindor, K., Tuscano, J., Tsuneyama, K., Zhang, W., Ueno, Y., Dunn, R., Kehry, M., Coppel, R.L., Mackay, I.R. \& Gershwin, M.E. (2009a) B-cell depletion with anti-CD20 ameliorates autoimmune cholangitis but exacerbates colitis in transforming growth factor-beta receptor II dominant negative mice. Hepatology, 50, 1893-1903.

Moritoki, Y., Lian, Z.X., Wulff, H., Yang, G.X., Chuang, Y.H., Lan, R.Y., Ueno, Y., Ansari, A.A., Coppel, R.L., Mackay, I.R. \& Gershwin, M.E. (2007) AMA production in primary biliary cirrhosis is promoted by the TLR9 ligand $\mathrm{CpG}$ and suppressed by potassium channel blockers. Hepatology, 45, 314-322.

Moritoki, Y., Zhang, W., Tsuneyama, K., Yoshida, K., Wakabayashi, K., Yang, G.X., Bowlus, C., Ridgway, W.M., Ueno, Y., Ansari, A.A., Coppel, R.L., Mackay, I.R., Flavell, R.A., Gershwin, M.E. \& Lian, Z.X. (2009b) B cells suppress the inflammatory response in a mouse model of primary biliary cirrhosis. Gastroenterology, 136, 1037-1047.

Nagasaki, F., Ueno, Y., Niitsuma, H., Inoue, J., Kogure, T., Fukushima, K., Kobayashi, K. \& Shimosegawa, T. (2008) Analysis of the entire nucleotide sequence of hepatitis B causing consecutive cases of fatal fulminant hepatitis in Miyagi Prefecture Japan. J. Med. Virol., 80, 967-973.

Nakagome, Y., Ueno, Y., Kogure, T., Fukushima, K., Moritoki, Y., Ridgway, W.M., Eric Gershwin, M. \& Shimosegawa, T. (2007) Autoimmune cholangitis in NOD.c3c4 mice is associated with cholangiocyte-specific Fas antigen deficiency. J. Autoimmun., 29, 20-29.

Ninomiya, M., Ueno, Y. \& Shimosegawa, T. (2012) PBC: animal models of cholangiopathies and possible endogenous viral infections. Int. J. Hepatol., 2012, 649290.

Obara, N., Fukushima, K., Ueno, Y., Wakui, Y., Kimura, O., Tamai, K., Kakazu, E., Inoue, J., Kondo, Y., Ogawa, N., Sato, K.,
Tsuduki, T., Ishida, K. \& Shimosegawa, T. (2010) Possible involvement and the mechanisms of excess trans-fatty acid consumption in severe NAFLD in mice. J. Hepatol., 53, 326-334.

Poupon, R.E., Lindor, K.D., Cauch-Dudek, K., Dickson, E.R., Poupon, R. \& Heathcote, E.J. (1997) Combined analysis of randomized controlled trials of ursodeoxycholic acid in primary biliary cirrhosis. Gastroenterology, 113, 884-890.

Roberts, S.K., Yano, M., Ueno, Y., Pham, L., Alpini, G., Agre, P. \& LaRusso, N.F. (1994) Cholangiocytes express the aquaporin CHIP and transport water via a channel-mediated mechanism. Proc. Natl. Acad. Sci. USA, 91, 13009-13013.

Tamai, K., Fukushima, K., Ueno, Y., Moritoki, Y., Yamagiwa, Y., Kanno, N., Jefferson, D.M. \& Shimosegawa, T. (2006) Differential expressions of aquaporin proteins in human cholestatic liver diseases. Hepatol. Res., 34, 99-103.

Ueno, Y., Alpini, G., Yahagi, K., Kanno, N., Moritoki, Y., Fukushima, K., Glaser, S., LeSage, G. \& Shimosegawa, T. (2003) Evaluation of differential gene expression by microarray analysis in small and large cholangiocytes isolated from normal mice. Liver Int., 23, 449-459.

Ueno, Y., Ambrosini, Y.M., Moritoki, Y., Ridgway, W.M. \& Gershwin, M.E. (2010) Murine models of autoimmune cholangitis. Curr. Opin. Gastroenterol., 26, 274-279.

Ueno, Y., Ishii, M., Yahagi, K., Mano, Y., Kisara, N., Nakamura, N., Shimosegawa, T., Toyota, T. \& Nagata, S. (2000) Fasmediated cholangiopathy in the murine model of graft versus host disease. Hepatology, 31, 966-974.

Ueno, Y., Moritoki, Y., Shimosegawa, T. \& Gershwin, M.E. (2007) Primary biliary cirrhosis: what we know and what we want to know about human PBC and spontaneous PBC mouse models. J. Gastroenterol., 42, 189-195.

Ueno, Y., Phillips, J.O., Ludwig, J., Lichtman, S.N. \& LaRusso, N.F. (1996) Development and characterization of a rodent model of immune-mediated cholangitis. Proc. Natl. Acad. Sci. USA, 93, 216-220.

Ueno, Y., Sollano, J.D. \& Farrell, G.C. (2009) Prevention of hepatocellular carcinoma complicating chronic hepatitis C. $J$. Gastroenterol. Hepatol., 24, 531-536.

Xu, L., Shen, Z., Guo, L., Fodera, B., Keogh, A., Joplin, R., O’Donnell, B., Aitken, J., Carman, W., Neuberger, J. \& Mason, A. (2003) Does a betaretrovirus infection trigger primary biliary cirrhosis? Proc. Natl. Acad. Sci. USA, 100, 8454-8459. 